AFRICAN

\title{
Policies, achievements and problems of full-time higher vocational education teacher development in China: 1983-2013*
}

\author{
by Wang Qi** \\ Institute of Higher Education, Ningbo Polytechnic \\ Ningbo, People's Republic of China \\ by Zhang Juxia*** \\ Institute of Higher Education, Ningbo Polytechnic \\ Ningbo, People's Republic of China
}

\begin{abstract}
Through analysis of policies of China's higher vocational education (HVE) from 1983 to 2013, we find that full-time teachers at vocational colleges have undergone

* Research funds: Research Project in Humanities and Social Sciences Sponsored by MOE Special Fund for Young Scholars 2014, Occupational Adaptation of Newly Employed Vocational College Teachers: Difference Analysis and Improvement Strategies (project ID: 14YJC880078): Key Projects of Key Humanities and Social Sciences Research Bases of MOE 2014: Ideology, Connotation and Driving Force of University Teacher Development (project ID: 14JJD880003).

** Wang Qi is the Deputy Director of the Institute of Higher Education at Ningbo Polytechnic, and a research fellow of the Vocational Education Institute for Developing Countries.

*** Zhang Juxia is a Research Assistant of the Institute of Higher Education at Ningbo Polytechnic and a research fellow of the Vocational Education Institute for Developing Countries.
\end{abstract}


four stages of development: conceptual exploration of full-time teacher development, forming of the notion "dually-qualified teachers", clarification of the notion "duallyqualified teachers", and - development of formal training systems and platforms for "dually qualified teachers". This process has seen a rapid expansion in the number of full-time teachers in HVE institutions, as well as great improvement in the overall quality of these teachers. There are, however, several areas which require improvement. There still exists a lack of professional standards for these teachers' performance, weakness of research ability of these teachers, and low efficiency of programs fostering "dually qualified teachers". In the future more efforts should be made to accelerate composition of professional standards for full-time teachers in HVE institutions and to improve their practical skills and applied research abilities.

\section{Introduction}

As a new form of higher education, China's higher vocational education (HVE) dates back to 1980. In the course of more than 30 years of development, from 1982 to 2013, China's higher vocational education has provided 28.1 million graduates, accounting for 43.51 per cent of higher education graduates (see Figure 1), which has greatly promoted the development of the economy and society.

China's HVE has played an important role in promoting social class upward mobility. According to MyCOS survey figures, 88.1 per cent of the vocational college students who graduated in 2011 were the first college students in their families, a record that has been maintained for three consecutive years from 2009 to 2011. It has been reckoned that in those three years close to 8.5 million families had produced their first generation of college students (Shanghai Academy of Education Sciences \& MyCOS Institute, 2012).

China's HVE has also played an important role in training talents for underdeveloped regions. Of the total number of students who graduated in 2011 from vocational colleges, 12.7 per cent came from impoverished areas, 22.2 per cent from the western regions, and 16.2 per cent from minority-inhabited regions 


\section{AFRICAN \\ EAST-ASIAN \\ AFFAIRS

(Shanghai Academy of Education Sciences \& MyCOS Institute, 2012). In 2013, 67 per cent of the graduates from vocational colleges in middle and western regions were employed in local areas. In some ways, the HVE has met the needs of the underprivileged and the poor for higher education. (Shanghai Academy of Education Sciences \& MyCOS Institute, 2014).

Figure1: Number of graduates from HVE institutions and all HE institutions in China: 1983-2013 (thousand people)

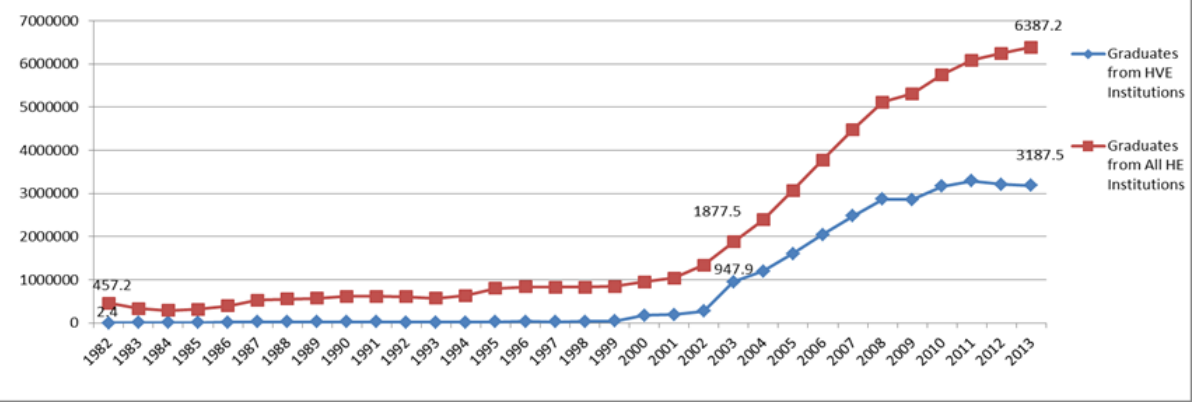

Source: data for 1983-1986, from China Education Yearbook 1982-1984 and China Education Yearbook 1985-1986; data for 1987-2013, from the annual China Education Statistics Yearbook of those years.

By the end of 2013, there were 1321 HVE colleges, in which 1108 specialties and 47,347 programs were being provided, and 9,736,373 students were being trained in China. The HVE system has gradually been improved. The HVE has become an important part of higher education, and played an increasingly important role in the whole education system (Figure 2). The tremendous achievement is inseparable from the teachers from HVE colleges, who have made a great contribution to the development of HVE. Meanwhile, the team of teachers in HVE has also improved a lot during the period. 
AFRICAN

EAST-ASIAN

AFFAIRS

\section{Figure 2: A diagram of the Chinese vocational education system}

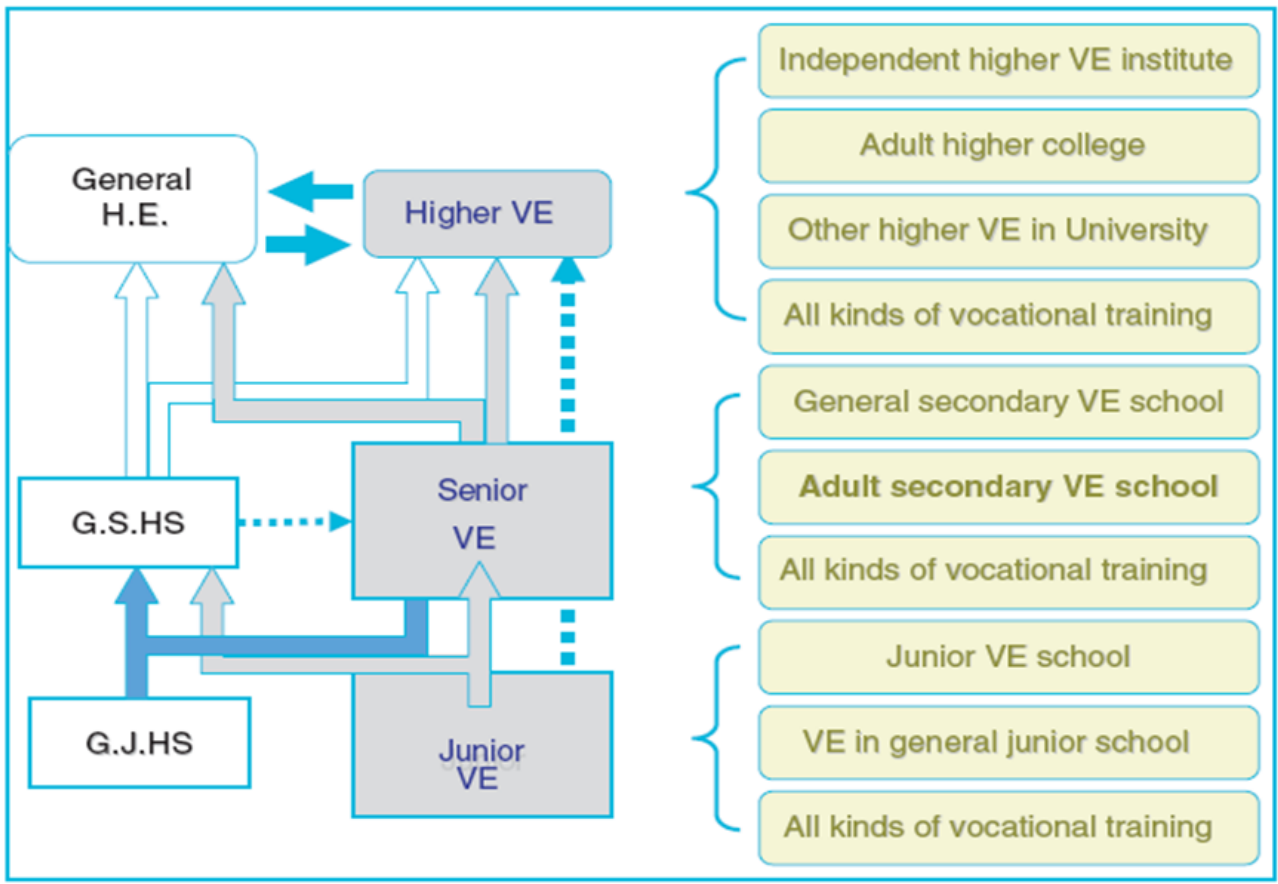

Source: Mi.J. and Wu, A. (2009).China's higher technical and vocational education: Development and reform. In Maclean,R. and Wilson, D. (Eds.) International Handbook of Education for the Changing World of Work (pp. 649-657).

Since HVE's first appearance, China has been exploring ways to cultivate full-time teachers for it. After combing through all relevant policies over the past three decades, four stages were identified in its full-time teacher development: conceptual exploration of full-time teacher development, forming of the notion "dually-qualified teachers", clarification of the notion "dually-qualified teachers", and development of a formal training system and platforms for "dually qualified teachers". The first 


\section{AFRICAN \\ EAST-ASIAN \\ AFFAIRS \\ THE CHINA MONITOR}

stage, conceptual exploration of full-time teachers' development, happened from 1983 to 1990 when no national policies had stipulated specific requirements for fulltime teachers in China's vocational colleges, but some vocational colleges had emphasized the requirement of "being competent to guide students' practical training" on their full-time teachers. Then, in the second stage from 1991 to 1999, the requirement of "dual qualification" had gradually been accepted by vocational colleges and included in national policies, in which employing a certain percent of "dually-qualified teachers" was defined as a basic requirement for establishing and running a vocational college, but no clear definition or standards of "dually-qualified teachers" had been set up until the third stage from 2000 to 2004, clarification of the concept of "dually-qualified teachers." In 2004, Assessment Scheme for Students Training in Vocational Colleges (trial version) formulated by Ministry of Education (MOE) of the People's Republic of China (PRC) codified the concept of "duallyqualified teachers" from perspectives of professional qualification, industrial experience, technical training, abilities to carry out applied research or R\&D, and defined the concept and criteria for assessing "dually-qualified teachers" officially. Since 2005, however, government policies turned to focus on how to train "duallyqualified teachers" in both practical competencies in the industry and practical training competencies in colleges, such as setting up a system for teachers' going back to industries, establishing on-job training bases for teachers, and so on.

Coupled with policy evolution is the continuous expansion of China's full-time teachers in HVE institutions, especially after the Great Expansion of China' higher education in 1999. In 2013, the number of full-time teachers in China's vocational colleges reached 436,561, accounting for 29.17 per cent of the total number of fulltime teachers in all Chinese institutions of higher learning. Meanwhile, quality improvement was also seen among full-time teachers in HVE institutions, with the percentage of "dually-qualified teachers" reaching 57.2 per cent of the total of fulltime teachers in HVE institutions. However, the teacher-student ratio in China's vocational colleges has stayed above 120 since 2003, signifying a lack of teachers even after part-time teachers from industries are also included. 
There are however several problems in development of full-time teachers in HVE institutions which are in an urgent need for improvement. These problems are a) a lack of national professional standards for employment and promotion; b) little attention on teachers' research abilities by HVE policies and practices and consequently weak research abilities; c) weakness of practical competencies in a corporate environment though "dual qualification" has been remarkably advanced.

Therefore, entry requirements and promotion criteria should be formulated as soon as possible by the Chinese government together with industries and vocational colleges. Meanwhile, a system should be established to promote co-operation between colleges and industries where full-time teachers can advance their practical competencies by getting involved in industries' practice. Finally, attention should be placed on strengthening full-time teachers' research abilities. Full-time teachers should be encouraged to carry out applied research or R\&D so that their research abilities can improve, thus improving the quality of the whole team.

\section{Thirty years of policy evolution}

During the 30 years from 1983 to 2013, there were four stages about the teachers' development in HVE in China, namely stages of conceptual exploration of full-time teachers' development, forming of the notion "dually-qualified teachers", clarification of the notion "dually-qualified teachers" and the development of formal training system and platforms for "dually-qualified teachers".

\section{The first stage from 1983 to 1990: conceptual exploration of full-time teachers' development}

Following China's first vocational college, Jinling Vocational College in City of Nanjing, Jiangsu Province, were establishment as part of the first batch of thirteen vocational colleges approved by the National Education Committee (former name of MOE) in 1980. Born out of practical needs, these vocational colleges followed a bottom-top development route. Consequently, no national guidelines were formulated for their development, let alone nationally standardised requirements for teachers in vocational colleges until 1982 when "Interim Regulations on Vocational 


\section{AFRICAN \\ EAST-ASIAN \\ AFFAIRS

Colleges in Jiangsu Province" was published, calling for "fostering a contingent of vocational teachers with devotion to China's educational cause as well as teaching competencies so as to maintain normal orders of teaching, to systematically summarise teaching experience, to continuously improve teaching practice and quality, "and suggesting employment of part-time teachers where necessary. The regulations also demanded full-time teachers in vocational colleges be assessed and conferred with academic titles or technical titles in line with relevant rules and requirements set up by MOE” (Ye Chunsheng, 2004) .

At that time, the differences between HVE and general higher education were identified in students training objectives, teaching processes and quality requirements on full-time teachers. For instance, Jianghan College, one in the first batch of vocational colleges founded in 1980, identified, in its college experience retrospect in 1986, two key competencies for teachers in HVE institutions: competencies to transmit knowledge and to guide students' practice (Chen Yingjie,2007). Unlike six years earlier, vocational colleges have since realised the importance of their teachers having competencies to guide students' practice, though little theoretical research and very few state policies have touched upon what elements comprise the competencies and how to develop the competencies among teachers.

\section{The second stage from 1991 to 1999-- forming of the notion "dually- qualified teachers"}

The notion "dually-qualified teachers" was first defined as "engineers and teachers" in an article published in 1991 featuring teacher development experience of Shanghai Metallurgy College. It pointed out:

The key factor for setting a tertiary technical college apart from universities is to foster a contingent of 'dually-qualified teachers' who master both knowledge and ability to put knowledge into practice. (Wang Yicheng,1991)

This article signified the commencement of research into the topic of "duallyqualified teachers" in China's vocational education, followed by a gradually 
increasing number of issues on the necessity of a contingent of "dually-qualified teachers" in vocational colleges (Zhou Mingxing, 2009). Then in 1994, Opinions of the State Council on Implementing the National Outline for Education Reform and Development mentioned that:

Entry criteria for vocational teachers should be formulated in line with characteristics of vocational education, and full-time technical teachers in vocational institutions could apply for both academic titles and technical titles. (The State Council, P.R.C.,1994)

One year later, the Circular Concerning Model Vocational Colleges Development Project, promulgated by the National Education Committee, set up a basic requirement for vocational colleges: they must have a team of teachers with an appropriate ratio between full-time teachers and part-time teachers, and with remarkable aptitude, of which over one third is "dually-qualified teachers" and in which both specialized course instructors and practical training instructors have ample practical competencies. It was the first time a national policy mentioned the concept of "dually-qualified teachers" and set it up as an objective for full-time teacher development in vocational colleges, and in the whole vocational education field. By then, though the concept of "dually-qualified teachers" had been put forward in government policies, apart from the emphasis on teachers' "technological application" and "practical competencies", no detailed statements had been made concerning clear definition or standards of "dually-qualified teachers."

\section{The third stage from 2000 to 2004--clarification of the notion "dually- qualified teachers"}

Due to lack of clear definition, the term of "dually-qualified teachers" was only interpreted as teachers with both teaching qualification and other occupational qualifications (for example an engineering qualification). This misinterpretation was seen in such government policies as a) Decision on Deepening Educational Reform and Promoting Quality-Oriented Education promulgated by CPC Central Committee in 1999, which demanded excellent engineering and administrative professionals from industries be attracted into serving as teachers in vocational institutions while 


\section{AFRICAN \\ EAST-ASIAN \\ AFFAIRS \\ THE CHINA MONITOR}

the building of a contingent of "dually-qualified teachers" with both teaching qualification and other occupational qualifications be sped up; b) Opinions on Strengthening Teaching Staff Training in Vocational Colleges issued by MOE in January 2000, which defined "dually-qualified teachers" as "teachers who are also engineers, accountants, and so on" (the MOE, 2000).

Different criteria for "dually-qualified teachers" were put forward in MOE's Circular on Carrying out Research into cultivation of Teachers in Higher Vocational Education Institutions and Junior Colleges issued in March, 2000:

"dually-qualified" full-time teachers of engineering disciplines must either a) have two years or more of engineering work experience and be able to guide practical trainings in their area of study, or b) have chaired (or participated as a key member) at least two engineering researches or development projects or at least two laboratory revamping projects, and have published two scientific and technological papers on college-level journals or above. These criteria can serve as a reference for other non-engineering disciplines.

It was the first national policy clarifying the meaning of "dually-qualified teachers" though a slightly different term of "teachers with dual qualifications" was adopted by the Circular. These criteria pinpointed the connotation of "dually-qualified teachers" from the perspective of qualification mix and highlighted the importance of teachers' practical competencies in a particular field. These criteria are more operable in that it focused on measuring teachers' industrial experience and scientific -technological R\&D abilities (SUN Cui-xiang \& LU Shuang-ying, 2013).

A more detailed definition of "dually-qualified teachers" was given in 2004 by MOE's Scheme for Assessing Students Training Quality in Vocational Colleges (trial version)

"dually-qualified teachers" are those teachers who have an academic title of lecture or above, and meet at least one of following requirements: a) having intermediate or above technical titles (or qualification certificates, titles of occupational certificate assessor or vocational skill assessor) in their field of study; 
b) within the last five years having at least two cumulative years of working experience in industries relevant to their field of study, or having attended vocational skills training programs organized by MOE and received certificates signifying the abilities to guide students' practical training of all kinds; c) having chaired (or participated as a key member) at least two applied researches within the last five years and the research results have been utilized by industries and have achieved great benefits; d) having chaired (or participated as a key member) at least two on-campus practical training facility construction projects or technological upgrading of on-campus practical training facilities, enabling those facilities to function better than those in other vocational colleges of this kind in province areas (the MOE, 2004) .

This is the most detailed interpretation of "dually-qualified teachers" by government policies since its conception and is also the official guideline currently in effect for vocational college accreditation and full-time teacher development in these institutions.

\section{The fourth stage since 2005--development of formal training system and platforms for "dually-qualified teachers"}

The clarification of "dually-qualified teachers" (dual qualifications) served as a guidance for "dually-qualified teachers" training. Since 2004, the focus of governmental files and policies has been shifted to training of "dually-qualified teachers," instead of its definition. Decision of the State Council on Vigorously Developing the Vocational Education, promulgated in 2005, and clearly stated that the country should:

Implement a teacher quality improvement scheme for HVE institutions while financial departments of local governments should provide financial support continuously to teacher training and training centre building. A system should be set up to encourage teachers to go back to the front line of production or service for at least two months every two years to get industrial practice.

It was the first requirement in national policy for teachers in HVE institutions to 


\section{AFRICAN \\ EAST-ASIAN \\ AFFAIRS \\ THE CHINA MONITOR}

obtain industrial practice and it was subsequently institutionalised. Following policies mostly focused on how to improve quality and practical competencies of teachers" with "dual qualification" by establishing a college-industry co-operation and platforms for teachers' industrial practice. For example, Several Opinions on Improving the Overall Educational and Instructional Qualities of Higher Vocational Education, issued by MOE in 2006, stated that "on-job practice in industries should be arranged for teachers with a view to gaining practical experience and hence improving practical training competencies" (the MOE, 2006), while the National Outline for Medium and Long-term Education Reform and Development (20102020), Promulgated in 2010, called for:

a) Development of "dually-qualified teachers" and practical training centres for students, b) improvement of fundamental capabilities of vocational education, c) building of "dually-qualified teachers" training centre with the joint efforts of higher education institutions and both large and medium-sized enterprises, and d) perfection of the system for teachers' regular industrial practice. (The State Council, 2010)

Opinion on Further Improvement of Training System for Vocational Education Teachers, promulgated by MOE in 2011, proposed a training system via collegeindustry co-operation, in particular by taking advantage of both large and mediumsized enterprises, provision of a group of "dually-qualified teachers" training centres and partner enterprises for vocational teachers' industrial practice. It was stressed again in Decision of the State Council on Accelerating Development of Modern Vocational Education, issued in 2014,

Implementation of a system for teachers to obtain industrial practice and construction of teacher training centres by the joint efforts of top-quality vocational colleges and both large and medium-sized enterprises. (the State Council, 2014)

Through retrospection of the above relevant policies, we can conclude that over the past three decades the objectives of teacher development in HVE institutions has been gradually clarified and teachers' industrial/practical competencies increasingly 
valued. Since its invention, the notion "dually-qualified teachers", as a key topic for governmental policies, has been continuously highly valued by governmental policies and its interpretation also steadily improved, by governmental policies. Along with this the policy focus shifted from what teachers vocational colleges need, to how to evaluate teachers' "dual qualification", and then how to help teachers advance their "dual qualification". These policies covered not only the definition, standards, number, training of "dually-qualified teachers", but also system for "dually-qualified teachers" training (SUN Cui-xiang \& LU Shuang-ying, 2013). Nowadays cultivation of "dually-qualified teachers" with both practical competencies in industry and teaching competencies has become the core of all policies in the field.

\section{Achievements both in quantity and quality}

During the evolution over the last 30 years, there were also great achievements both in quantity and quality regarding the full-time teachers in HVE. The number of teacher teams was increasingly expanded and the quality was steadily improved.

Achievements in quantity: the continuously increasing total number of full-time teachers

In 1983, a small number of 54 vocational colleges (then named as short-cycle term vocational colleges) employed 2321 full-time teachers, only accounting for 0.77 per cent of the total number of teachers employed by all institutions of higher learning. Since then, the number of vocational colleges has been continuously increasing while its teacher cohorts have been continuously expanding. Especially after the 1990s when the Chinese economy started to take off and industries began needing more skilled workers, increased importance was attached to vocational education. A decision (termed as "three revamping and one supplementing") was endorsed in the early 1990 s by the government, suggesting that:

HVE can be developed by reform, reorganization and transformation of existing occupation university, post-secondary junior colleges and universities for self-taught adults, and that if all these are not enough, the shortfalls be filled by 


\section{AFRICAN \\ EAST-ASIAN \\ AFFAIRS

upgrading a small number of authorized key vocational high schools. (Li Lanqing, 2003)

Pushed by this decision, HVE as a whole witnessed a rapid expansion in the middle and late years of the 1990s. In 1998, Higher Vocational Education Division, also responsible for development planning and governance of post-secondary junior colleges, besides those of vocational colleges, was set up under the MOE, resulting in the reform of some post-secondary junior colleges towards vocation-oriented colleges and a sharp increase in the number of both vocational colleges and their full -time teachers. Moreover, a surge in the number of both vocational colleges and consequently of their full-time teachers was witnessed in 1999 when China started its great expansion in higher education, in which a majority of the enrolment quota

\section{Figure 3: Number of Full-time Teachers in HVE Institutions in China: 1983- 2013 (thousand people)}

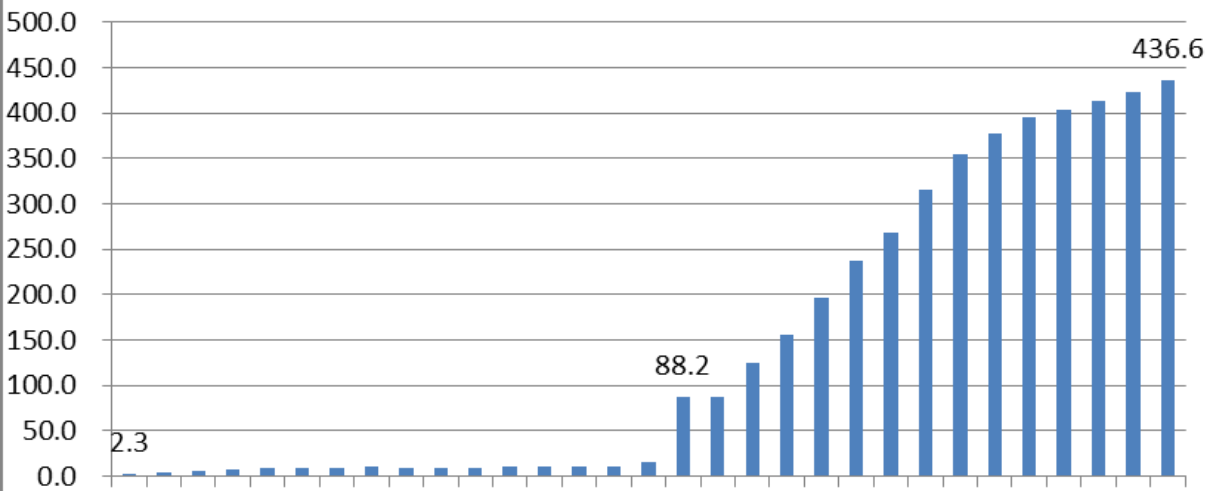

1983198519871989199119931995199719992001200320052007200920112013

Source: data for 1983-1986, from China Education Yearbook 1982-1984 and

China Education Yearbook 1985-1986; data for 1987-2013, from the annual China Education Statistics Yearbook of those years. 
AFRICAN

EAST-ASIAN

AFFAIRS

was given to vocational colleges. In 1999, the number of full-time teachers in HVE institutions reached 88,206 , accounting for 20.72 per cent of the total $(425,682)$ in all

Figure 4: Ratio between Students and full-time Teachers in China's HVE Institutions: 1983-2013

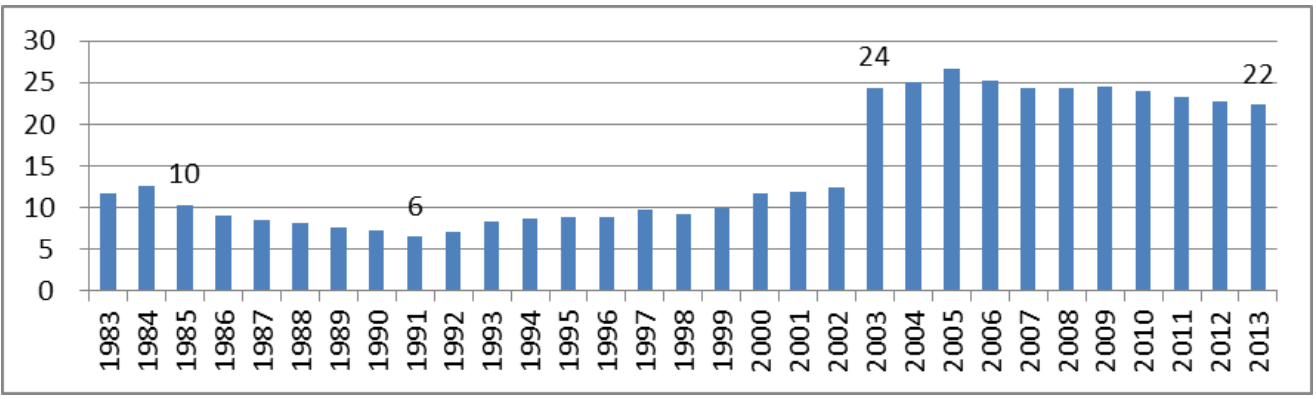

Source: data for 1983-1986, from China Education Yearbook 1982-1984 and China

Education Yearbook 1985-1986; data for 1987-2013, from the annual China Education Statistics Yearbook of those years.

institutions of higher learning. The number increased steadily to 436,561 in 2013, accounting for 29.17 per cent of the total (see Figure 3).

Though noticeable, the surge in the number of full-time teachers lagged far behind the surge in student enrolment. As a result, teacher-student ratio reached 1:24 in 2003, but has been below 1:20 since then. It is alarmingly low even after taking into account of the number of part-time teachers (see Figure 4).

\section{Steady improvement of quality}

Along with growth in figure, the quality of full-time teachers in HVE institutions also went through a steady advance. A point in case is their academic titles, with the percentage of senior academic title (professors and equivalent level, and associate professors and equivalent level) holders elevated from 5.81 per cent in 1987 to 29.28 per cent in 2013 (see Figure 5). 


\begin{tabular}{|c|} 
AFRICAN \\
EAST-ASIAN \\
AFFAIRS \\
\hline THE CHINA MONITOR \\
\hline
\end{tabular}

A non-stop increase was also seen in the number of teachers with industrial practical experience. The percentage of "dually-qualified teachers" reached 28.4 per cent (Ma Shuchao, 2009) in 2007 and then 57.2 per cent in 2013, even over 70 per cent in

Figure 5: Percentage of full-time teachers with senior academic titles in China's HVE institutions: 1987-2013

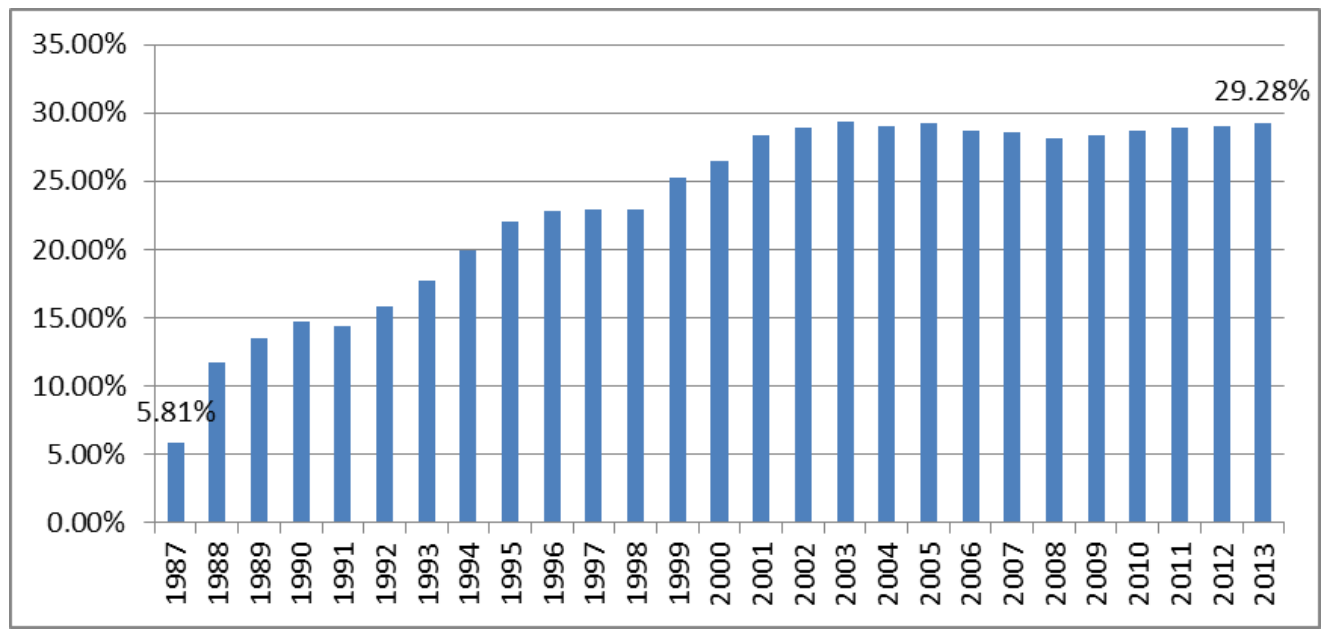

Source: annual China Education Statistics Yearbook of those years.

some provinces like Jiangsu, Zhejiang, and so on (Shanghai Academy of Educational Sciences \& MyCOS Institute, 2014).

\section{Problems that need urgent solutions}

There are also some problems regarding the teacher development in HVE, including no official standards for teacher development available, teachers' research and practical abilities still remain weak and so on.

\section{Lack of professional standards for teachers}


According to Ren and Sun (2009):

Professional standards are detailed description of skills, knowledge and behaviours required for entry into a particular profession and yardsticks against which applicants for the profession will be measured. (Ren Bo \& Sun Yvzhong, 2009)

In order to strengthen teachers' professional development, teachers' professional standards have been formulated in many developed countries, stipulating entry requirements in terms of knowledge, aptitude, skills, conduct codes and assessment criteria. Likewise, Professional Standards for Kindergarten Teachers (trial version), Professional Standards for Primary School Teachers (trial version), and Professional Standards for Secondary School Teachers (trial version) were promulgated by the MOE in China in 2012 to specify essential professional ideology, knowledge and competencies for teachers in kindergartens, primary schools, or secondary schools respectively. HVE, however, is a different level and type of education focusing on fostering students practical competencies. Therefore, teachers in HVE institutions are expected to have some special competencies for HVE, as well as general competencies required for all college teachers. Due to these differences, a unique set of professional standards should be established for teachers in HVE institutions. However, no sound professional standards are available in China for these teachers, and these teachers are still in the same track similar to those of other higher education institutions in terms of teacher certification, which have not yet taken HVE's unique features and demands into consideration. Even worse, the current teacher certification system only examines applicants' competencies before their entry into the profession, but no attention has been paid to ongoing assessment and upgrading along with teachers' professional development. Consequently, this lack of special professional standards for teachers in HVE institutions has disoriented those teachers along their professional development (Zhu Xuemei, 2010). 


\section{AFRICAN \\ EAST-ASIAN \\ AFFAIRS

\section{Negligence of teachers' scientific and technological research abilities improvement}

As one of three functions of higher education, scientific and technological research is a vital means for teachers in HVE institutions to improve their professional competencies. However, over the nearly thirty years of HVE development, and despite the advocacy of "production-teaching-research combination" in HVE, objection to knowledge-oriented and discipline-categorised courses have been the main theme in HVE's educational and instructional reform and in its teacher development drive whereas academic themes have been marginalised, hence scientific and technological research among the teachers has been weakened (Cheng Yikang, 2012). The status of scientific and technological research by teachers in HVE institutions was further lowered by a government policy publicised in 2006, Several Opinions on Improving the Overall Educational and Instructional Qualities of Higher Vocational Education, in which "research" was removed out of the "production-teaching-research combination" and another term "production-teaching combined approach" was proposed instead. Since then little efforts have been given to improve HVE teachers' scientific and technological research, although "research" was discussed again in following policies.

Applied technological invention and patents show teachers' practical competencies, technological application and R\&D abilities, and professional proficiency. We searched in the Patent Database under China National Knowledge Infrastructure (CNKI) by typing in key words such as "vocational and technical colleges" "vocational colleges", and "technical colleges" for patents for invention, exterior design or new applied techniques owned by teachers from these colleges. We found that 2,387 patents of the three kinds were conferred to full-time teachers from HVE institutions in 2011, which means 0.006 patents per full-time HVE teacher. Even if these patents were all from teachers of technological, engineering, agricultural, or medical subjects (accounting for about half of the total according to the China Education Statistics Yearbook 2011), subjects involving more technology which are more likely to contribute to technological advancement, the per capita 
average is just 0.012 , signifying huge room for improvement.

\section{More efforts should be made to reinforce the effectiveness of "dual qualification" training}

Involvement in industrial practice is the major approach for teachers in HVE institutions to improve their professional aptitude. In recent years, industrial working experience and practical competencies of some full-time teachers from HVE institutions have been improved via doing on-job industrial practicum. There are, however, some problems. First, no mature system has been established for teachers' deep involvement in industrial practice, therefore the effects of industrial practice vary greatly from institution to institution, from program to program, from individual teacher to individual teacher; second, for some teachers, industrial practicum only means looking around the industries and gaining some industrial working experience while only very few teachers, with excellent technological applications and R\&D abilities, can actively participate in enterprises' technical innovation and upgrading. A survey of "dually-qualified teachers" in vocational colleges in Jiangsu Province found that "32 per cent of all vocational college teachers in Jiangsu cannot learn or acquire new knowledge timely from production front lines, while 90 per cent or so of teachers are poor at operation and technique" (Cai Yi, Zhang Yiping \& Sun Xianshan, 2011), which, to some extent, reveals the problems faced by "dual qualification" project in vocational colleges.

\section{Unable to attract professionals from industry to teach in HVE colleges}

Professionals with high skills and rich experiences from industry are the best choice for higher vocational colleges to train their students to meet the need of industry. But just like in other countries around the world, professionals can earn more practicing their profession than they can teaching it. Salary of teachers in HVE colleges in China is just at medium level and less attractive to professionals than industry. So most the professionals with high skills are in the industry and there are few teachers in HVE colleges with skills meet the needs of industry. Therefore, the primary mission of the construction of "dual qualification" teachers' team is to improve the practical ability of the full-time teachers. For example, a new item is listed in the 


\section{AFRICAN \\ EAST-ASIAN \\ AFFAIRS

Modern Vocational Education Development Strategy 2014-2020 which requires the full-time professional teachers should practice their profession in industry no less than two months every two years. This is one of the reasons that account for the graduates from HVE colleges can't meet the needs of industry.

\section{Suggestions on teacher development in HVE institutions}

Based on the analysis above, we try to put forward some suggestions on teacher development in HVE, according to some policies published recently.

\section{Speed up the development of professional standards for teachers in HVE institutions}

The development of professional standards for teachers in HVE institutions has been prioritised by the government and proposed in government files such as the National Outline for Medium and Long-term Education Reform and Development (20102020) promulgated in 2010, asking for "the establishment of professional standards for teachers in HVE institutions correspondent to vocational education's features," and Decision of the State Council on Accelerating the Development of Modern Vocational Education in 2014, demanding "perfection of teacher qualification criteria and the establishment of professional standards for teachers". Policies also demanded that, in compliance with the characteristics and development orientation of HVE, the professional standards for HVE teachers are expected to emphasise "dual qualification." In terms of knowledge requirements, these professional standards should highlight teachers' mastering of technical and industrial knowledge; as for research ability, these professional standards should focus on technological application and R\&D abilities, abilities to apply their research results in enterprises' production, technological renovation and products upgrading; and as for teaching competencies, teachers' practical training competencies and their guidance in students' practical training should be underscored to meet the mission of HVE: training skilled manpower. 


\section{To further college-industry co-operation to better enhance teachers' practical competencies}

Working experience in industries and knowing production technologies and operating procedures of a company is an important indicator of professional aptitude of teachers' in HVE institutions. However, professional aptitude should not be defined only as having working experience in industries and obtaining certain technical expertise and practical skills, otherwise teachers would be directed towards becoming technicians (Song Qinglong, 2007), which is inconsistent with HVE's orientation as tertiary education. The core of teachers' practical competencies is the ability to serve industries and businesses, which in turn enable teachers to update their working experience, and then their teaching content, thus providing improved training quality. Serving industries and businesses, means that you get involved in enterprises' technical renovation and $\mathrm{R} \& \mathrm{D}$, to provide technical support and consultancy to enterprises, even to lead the enterprises' technical development, as well as to master technical expertise in that industry. Therefore, HVE institutions should put more emphasis on teachers' practical competencies and R\&D abilities instead of their working experience in industries. Moreover college-industry cooperation mechanisms should be set up to guide teachers' active involvement in production and R\&D of enterprises and increase the effectiveness of the teachers' practicum by means of deepening the teacher-enterprise co-operation in $R \& D$ as well as enhancing their practical expertise.

\section{To guide teachers' applied research}

Teachers' participation in industries' applied research or R\&D, as a symbol of the two natures of HVE (tertiary and vocational) and an essential goal of HVE development, is not only an effective way for teachers to enhance their practical skills and their ability to serve enterprise but also an effective way to improve the overall quality of HVE. It is beneficial to both HVE institutions and teachers. For HVE institutions, teachers' participation in industry-demanded applied research or $\mathrm{R} \& \mathrm{D}$ can guarantee sustainable and deep college-enterprise co-operation, hence improved student training quality. On the teachers' part, applied research or R\&D 


\section{AFRICAN \\ EAST-ASIAN \\ AFFAIRS

can greatly enhance their academic expertise, knowledge teaching, and confidence in academic research. Therefore under the circumstance where quality development is stressed, great efforts should be made in both governmental policy and college policy to guide teachers towards applied research and towards research abilities improvement. It should be noted, however, that applied research in HVE should focus on applied research driven by industrial needs, and on didactic research to improve actual instruction. Meanwhile, research and teaching should be wellbalanced, instead of stressing research while neglecting teaching.

\section{To construct motivation systems to attract professionals from industry to}

\section{teach in HVE colleges}

China needs to establish multi-sectorial promotion policies, such as policies established by the MOE, the Ministry of Human Resources and Social Security (MOHESS), and the National Development and Reform Commission (NDRC), to attract more professionals from business to teach in HVE colleges. Policies should set a series of salary standards to encourage professionals from industry to teach in HVE colleges, as well as to reward or provide promotion priorities to those whose teach in colleges part-time. Meanwhile, more authority should be delegated to colleges permitting them to employ professionals as full-time teachers at a high salary. It is also a good way to attract professionals to employ as part-time teachers. With a principal of not-for-possession-but-for-using, colleges should employ some professionals with high skills from industry.

\section{Conclusions}

1. Conceptually, a principle has been shaped for full-time teacher development in HVE institutions, namely individual full-time teachers should have "dual qualifications" while "dually-qualified teachers" should account for the majority of a teacher cohort.

2. The number of full-time teachers in HVE institutions has greatly increased, now accounting for 29.17 per cent the total in all institutions of higher learning. Compared with the percentage of HVE enrolment, 50 per cent of the total higher 
AFRICAN

EAST-ASIAN

AFFAIRS

education enrolment, there is a lack of teachers, even part-time teachers from industry.

3. Great progress has been made in faculty quality with sharp increases in the percentage of both senior academic title holders and "dually-qualified teachers". Nevertheless, more efforts should be made to further improve teachers' practical competencies, and applied research abilities in particular so that they can participate actively in industrial production and technical research. Meanwhile, policies should be established by several sectors jointly, such as the MOE, the MOHESS, and the NDRC, to motivate professionals to teach in colleges.

4. No national professional standards for full-time HVE teacher development are available. Government is expected to work together with industries and HVE institutions to formulate criteria for entrance and promotion of teachers, and to regulate the development of full-time teachers in order to promote the quality of the team.

\section{Bibliography}

Cai, Y., Zhang, Y. and Sun, X. 2011. Problems Faced by "Dually-qualified Teacher" Development in Vocational Colleges and Their solutions--from a Field Survey of Jiangsu. Journal of National Academy of Education Administration, 21(6): 29-32.

Chen, Y. 2007. Development History of China's Higher Vocational Education. Zhongzhou: Zhongzhou Ancient Book Press.

Cheng, Y. 2012. HVE teachers' Professional Development Based on Multidimensional Academic View. Journal of National Academy of Education Administration, 22(5): 22-26.

He, D. 2003. Important educational documents of P.R.C. (1998-2002). Haikou: Hainan Press. 
AFRICAN

Li, L. 2003. An Interview with Li Lanqing on Education. Beijing: People's Education Press.

Ma, S. 2009. Historical Choices of China's Higher Vocational Education. Beijing: Higher Education Press

Mi, J. and Wu, A. 2009.China's higher technical and vocational education:

Development and reform, in R. Maclean and D, Wilson (eds.). International

Handbook of Education for the Changing World of Work. Berlin: Springer. 649-657.

Ren, B. and Sun, Y. 2009. Constructing Professional Standards for HVE teachers. China Higher Education, 359(1): 49-50.

Shanghai Academy of Educational Sciences and MyCOS Institute. 2012. 2012 Annual Report on Technical and Vocational Higher Education in China. Beijing: Foreign Language Teaching and Research Press.

Shanghai Academy of Educational Sciences and MyCOS Institute. 2014. 2014 Annual Report on Technical and Vocational Higher Education in China. Beijing: Higher Education Press.

Song, Q. 2007. Several Problems Faced by HVE Teachers' Professional Development. Wuhan: Central China Normal University.

Sun, C. and Lu, S. 2013. Changes of "Dual-qualification" Teacher Policy: Process, Characteristics and Future Trends. Vocational and Technical Education, 34 (28): 48-54.

The MOE, P.R.C. 2000. The MOE Circular on Carrying out Overall Students Training Quality Assessment in Vocational Colleges [Online]. Available: http://www.moe.edu.cn/publicfiles/business/htmlfiles/moe/ moe_42/201010/110099.html [2015, November 20].

The MOE, P.R.C. 2006. Several Opinions on Improving the Overall Educational and Instructional Qualities of Higher Vocational Education [Online]. 
AFRICAN

EAST-ASIAN

AFFAIRS

Available: http://www.moe.edu.cn/publicfiles/business/htmlfiles/moe/ moe_745/200612/19288.html [2015, November 20].

The MOE, P.R.C.2011. Opinion on Further Improvement of the Training System for Vocational Education Teachers. [Online]. Available: http://www.moe.edu.cn/ publicfiles/business/htmlfiles/moe/moe_960/201201/xxgk_129037.html html [2015, November 20].

The State Council, P.R.C. 2010. National Outline for Medium and Long-term Education Reform and Development (2010-2020) [Online]. Available: http:// www.moe.edu.cn/publicfiles/business/htmlfiles/moe/ moe_838/201008/93704.html [2015, November 20].

The State Council, P.R.C. 1994. Opinions of the State Council on Implementing the "National Outline for Education Reform and Development" [Online]. Available: http://www.moe.edu.cn/publicfiles/business/htmlfiles/moe/ moe_177/200407/2483.html [2015, November 20].

Wang, Y. 1991. To Develop a Contingent of "Dually Qualified Teachers". Researches in Engineering Higher Education, 9(2): 49-50.

Ye, C. 2004. Twenty Years of Practice and Exploration-- Collection of Essays on Higher Vocational Education. Beijing: Higher Education Press.

Zhou, M. 2009. 30 Years of Development of China's Vocational Education. Shanghai: Eastern China Normal University Press.

Zhu, X. 2010. Connotation and Framework of Teachers Professional Abilities of Higher Vocational Education. Vocational and Technical Education, 31(1): 56 -58 . 